\title{
Trend in Productivity research in Bangladesh Agriculture: A Review of selected Articles
}

\author{
Dr. Bilkis Raihana ${ }^{1}$
}

${ }^{1}$ Department of Economics, Asian University Bangladesh

\begin{abstract}
This study is exploratory in nature. Changes in productivity in Bangladesh agriculture are issues of continuing research and policy interest. This article aims at interpreting the trends of productivity studies in Bangladesh agriculture sector including techniques, methods and models. This will be pursued on the basis of literature review of published books, journals and materials. Recent research developments in the study of productivity measurement have emphasized two things: the superiority of Total factor productivity (TFP) indexes and the use of flexible weight indexing procedures. But most of the earlier research work in Bangladesh agriculture has not incorporated both these approaches simultaneously. Efforts have been made to provide some recommendations to enhance the productivity studies in Bangladesh agriculture
\end{abstract}

Keywords: Trends, Research, Productivity, Bangladesh agriculture

JEL Classification Code: Q13; Q15; O13

\section{INTRODUCTION}

$\mathrm{T}_{\mathrm{t}}^{\mathrm{H}}$ HE analysis of productivity change is of great importance from theoretical and empirical point of view. Bangladesh is predominantly an agricultural country. Since independence, a rapid expansion of fertilizer, irrigation and modern variety seeds caused technological transformation in Bangladesh agriculture and productivity advances due to technological improvements. It is worth studying whether productivity in Bangladesh agriculture is growing and if so, to what extent and whether the growth of output is greater than the growth of inputs.

Productivity can be defined as the relationship of output to the related inputs. Productivity measures can be divided into two categories - partial and total. The ratio of output to a particular input is known as partial factor productivity (PFP), such as the partial productivity of land, partial productivity of labour, partial productivity of fertilizer. On the contrary, the ratio of output to all productive inputs taken together is known as total factor productivity (TFP). Though the partial factor productivity (PFP) measure is widely used method, but it is, however, misleading to attribute increases in output solely to a particular input since this ignores the contribution of the increasing use of other inputs in production process. In recent years the TFP approach has gained popularity due to its ability to consider all productive inputs and TFP is a better indicator of physical (or technical) efficiency gains in production (Islam,1982).

There are two types of indexing procedures to construct the indexes of output and inputs whose ratio gives the index of productivity. The first is the fixed-weight approach, that is, the Laspeyres and Paasche indexes and the other is flexible-weight approach of which the Divisia index and its discrete Tornqvist approximation are most well-known in economic studies. In Bangladesh, the Laspeyres index is generally used by Bangladesh Bureau of Statistics (BBS). Though the Laspeyres index is widely used but it is sensitive to the choice of a base period while the construction of Divisia index requires both price and quantity data for each year in the time period and it is flexible enough to study changing input use (Islam, 1982).

In Bangladesh, several studies have been done in the field of agricultural productivity. Most of these studies are not conceptually or methodologically same. As improved measures, the application of total factor productivity and flexible weight indexing procedures in Bangladesh agricultural Productivity studies are very limited. The present study tries to review some of these studies to get a picture of productivity studies in Bangladesh agriculture and to find out the knowledge gap.

\section{OBJeCtive Of THE STUdY}

The main objective of this study is to review the productivity literature relating to existing theoretical models of productivity measurement and other perspective in Bangladesh agriculture. In this regard this paper tries to explore the adequacy of TFP indexes based on flexible-weight approach in Bangladesh agriculture sector. It also aims to make a critical appreciation of the different available research studies done earlier in the field of agricultural productivity.

\section{Methodology and Limitation of the study}

This study is descriptive in nature. A descriptive study tries to discover answers to the questions who, what, when, where and sometimes how. The present study is 
conducted on the basis of the secondary data and it is concerned with Bangladesh agricultural sector. On the basis of availability of data, accuracy of data, time span and cost factor of the study, secondary data play significant role in research (Sekaran, 2002). Data has been collected from the published research articles, different books and dissertations concerning the study.

The limitation of this study is that this study did not use primary data. Despite this limitation, the collected data have been processed manually and present form has been prepared in order to make the study more informative, analytical and useful for the users.

\section{Major Observation}

In recent years, both the field-level data and aggregate data have been used to study productivity in Bangladesh agriculture. The findings of these studies varied due to adoption of different procedures.

An early study of both partial factor productivity (PFP) and total factor productivity (TFP) in Bangladesh agriculture was conducted by Hossain (1973). This study is based on 95 farms of Phulpur in the Mymensingh district. In this study, productivity of land and labour was found to be highest for the 2.5 to 5.0 acre size group. On the other hand, this study indicated the relatively low productivity of land and labour in large farms. By considering the TFP in agriculture it was found that the 2.5 to 5.0 acre size group was the most efficient. In this study, there were indications that by increasing the percentage of land for the small farms, it might be possible to increase productivity and growth of agriculture.

Hossain (1977) studied productivity of land by adopting partial factor productivity (PFP) approach. Using farm level data of the Bangladesh agriculture sector, he classified the farms for calculation of land productivity. He found the difference in land productivity between owner I (land up to 6.5 acres) and owner II (land above 6.5 acres) and examined the inverse relationship between farm size and productivity. In this study, productivity of land was found higher for small owner-cultivators than the large owners.

Mandal (1980) observed the inverse relationship between farms size and productivity in Bangladesh agriculture. By using empirical data collected through a lengthy intensive farm survey in Mymensingh district, he found productivity per acre increased up to a certain level (about 4.0 acres), then it declined as farm size increased. Medium farms appeared as more productive than small and large farms. With the help of paired t-test, share cropping tenancy was found to be inefficient in resource use and production.

Abedin and Bose (1988) worked on the controversial issue of farm size and productivity relationship. The earlier studies did not give importance on the contribution of factors which created the differences among small, medium and large farms. In this study, they studied the relationship between farm size and productivity using the decomposition analysis. Using farm level data on irrigated HYV Aman rice in Thakurgaon, this study showed positive relationship between farm size and productivity.
In case of input use, the medium and large farms used more modern inputs, especially fertilizer, than the small farms. Both tabular and production function analysis were employed to estimate the productivities of small, medium and large farms and it was observed that large farms have a higher level of output per hectare than small and medium farms.

Hossain (1988) studied the effect of new technology on productivity of land and labour. By using farm level cross section data for 1982, he found that the sum of the output elasticities, that is, the factor shares of land and labour, is less than one for modern variety boro while it is greater than one for other varieties of rice. This study indicated that due to adoption of modern technology, a farmer might get increasing net returns from the land. But in case of increasing productivity of labour, the effect of modern technology was small.

Matin (1989) studied productivity of rice production using district level data for the period 1976-77 to1984-85. The effect of farm size and input use on the yield of rice was also analyzed in this study. A log (natural) linear transformation of the Cobb-Douglas production function has been estimated by the ordinary least method to find the effect of size and input use on the productivity of rice. This study showed the existence of positive sizeproductivity relationship and a weakening of inverse relationship of size-productivity was observed in this study and it happened due to appearance of technological changes in agricultural productivity.

Hossain (1990) studied the long-term growth performances of major agricultural crops and measured the differences in agricultural productivity among different regions of Bangladesh. This study was based on the data from 1949-50 to 1987-88. In this study, a poor performance in production of individual crops was observed which indicated an unsatisfactory growth in total crop output. This study also indicated the importance fertilizer and irrigation for increasing agricultural productivity. By considering the relative contribution of component elements for the crops it was observed that area expansion had the largest contribution to the change in output of boro while increase in output of aus and aman, the increasing productivity was found to have the largest contributor.

Hossain (1991) studied the performance of the crop sector of Bangladesh agriculture from 1967-70 to 1981-84 (period I) and from 1967-70 to $1985-88$ (period II). It is observed that during the period from 1967-70 to 1985-88, total crop output in Bangladesh agriculture increased by 1.53 percent per annum while the population growth rate was 2.70 percent per annum which indicated an unsatisfactory growth rate in the per capita output of the crop sector. This study examined the impact of seed-waterfertilizer technology on crops and observed that this program had no effect on the productivity of individual crops but an exception is found for rice, wheat, jute, rape and mustard and potatoes. As compared to period I, the magnitudes of positive productivity effect on the output growth of boro rice, wheat, jute, potatoes and tobacco were small and the intensities of negative productivity effect on 
sugarcane, garlic and groundnut were large in period II. Dey and Evenson (1991) used Tornqvist-Theil index to measure Total factor productivity (TFP) and reported TFP growth rate of rice was $0.94 \%$ for the period 1973-1989.

Pray and Ahmed (1991) applied Tornqvist-Theil index to measure Total factor productivity found TFP growth rate of Bangladesh agriculture was $0.32 \%$ per annum for the period 1948-1981.

Jahan (1997) estimated TFP and at the initial stages of using modern inputs, the growth rate in TFP showed increasing trend and since the 1980s TFP growth has tended to decelerate. With changing production technology a significant decline has occurred in the relative variability in TFP. This study also attempts to provide the relevant issues such as rural woman's participation rates, rural male and female differentials, decomposable measure of poverty and shares of the burden of poverty.

Coelli et al.(2003) applied a stochastic production function approach to measure TFP in Bangladesh crop agriculture for the period 1961-1992. He found TFP increased at a rate $0.23 \%$ per annum.

Taufique (2005) explains the relationship between size and productivity in Bangladesh agriculture by analyzing the transaction costs of employing labourers in a high (Madhupur) and a low (Chandina) potential area. In Madhupur, labourers are hired for task specific operations whereas in chandina they are hired on a daily wage basis. Thus larger firms in Madhupur can employ labour at a low transaction costs hence output per acre is higher as compared to smaller firms. In chandina the quality of supervision performed by family labourers falls as farm size increases and hence output per acre is lower as compared to smaller farms.

Rahman (2007) applied stochastic frontier production function approach to the analysis of efficiency, technical change and total factor productivity growth in agriculture sector for 16 regions of Bangladesh for 1964-1992 and explicitly test for existence of convergence in agricultural productivity among regions. He used the sequential malmquist index to calculate multilateral, multifactor productivity (MFP) indexes and found productivity grew at an average rate of $0.09 \%$ per annum and the overall productivity growth mainly occurred due to technological progress estimated at $1.9 \%$ per year which was then offset by declining technical efficiency $1.0 \%$ per year that exacerbated in most of the regions in latter years. The initial phase (1964-1975) achieved a modest TFP growth of $0.3 \%$ per annum due to technical progress while efficiency improvement powered the TFP growth rate at $1.9 \%$ per annum during (1985-1992) period.

Banerjee (2009), measured agricultural productivity in terms of the yield rate per acre of cropped land for rice (principle food crop) and jute (the principle cash crop). She used linear trend equation for the measurement of productivity and applied the least square with dummy variable (LSDV) method for estimation. Time series data on output produced per unit area under cultivation (in acres) in each district, by month over 1979-2000, is generated for each variety of rice (aus, aman and boro ) and each variety of jute (white and tossa). She found while agricultural prod- uctivity in Bangladesh has shown a positive trend, agricultural wage rate has been declining over the long run.

Baset et. al (2009) conducted a study of productivity growth in modern variety potato in Bangladesh agriculture. PFP and TFP index was estimated by using Tornqvist-Theil index formulation from 1981 to 2006. They also studied the extent of shift of production function or the supply curve of modern variety of potato in Bangladesh. A substantial change has been started from the year 199899. The trend of inputs used was found increasing. Almost all the partial as well as the input, output and total factor productivity indexes also found increasing.

In their paper, Asduzzaman et al. (2010) provided a brief history of growth on crop agriculture and its characteristics and the challenges that Bangladesh agriculture will face in future ( climate change)and the key issues that need resolution in order to face these challenges. For facing the challenges they suggested strategy and investment for coastal area agriculture, adoption of climate change, water use efficiency, overhaul the extension system, crop diversification and crop specialization, upgrade marketing services and reduce post harvest losses, integrated crop production strategy, development of new crop varieties, reliable supply of quality seeds, fertilizer and pesticides, maintenance soil health, modernize the agricultural education and training system, farmers organization etc. For longer term in agriculture sector they emphasized the well designed management of water resources and investment in adoption to climate change.

Khosruzzaman et al. (2010) studied energy intensity; energetic efficiency, energy productivity and the mechanization index have been evaluated for the period 1990 to2005 in Bangladesh agriculture. They found that energy intensity increased by 1.19 -fold while the energetic efficiency declined from 3.97 to 3.03 during study period. In 1990, the mechanization index was $64 \%$ and it rose to $78 \%$ showing a $22 \%$ increment compared to 1990 . In 1990 the energy productivity was $0.12 \%$ which declined to $0.11 \%$ in 2005 . The energy productivity declined with increasing energy input/ hectare.

Therefore, recent research developments in the study of productivity measurement (Christensen, 1975; Diewert, 1976; Brown 1978; Ali, 1991; Sharma, 2004; Kiani, A. et.al. 2008; and Ali, A. et al. 2009) have emphasized two things: the superiority of Total factor productivity (TFP) indexes and the use of flexible weight indexing procedures. Despite these developments, most of the existing research work on Bangladesh agriculture has not devoted to these approaches. This paper reveals this gap and points to the adequacy of TFP approach to examine the productivity in Bangladesh agriculture sector. The development of improved measures of productivity growth in Bangladesh agriculture is needed to show whether productivity growth has increased due to the adoption of modern technology.

\section{Recommendations}

In order to obtain significant result of productivity growth in Bangladesh agriculture sector some sugges- 
tions are provided:

1) TFP approach can be used in measuring productivity, though PFP is widely used as a precise method but in recent years the TFP approach has gained popularity due to its ability to consider all productive inputs

2) Since Laspeyres index is sensitive to the choice of a base period, flexible weight indexing procedures can be adopted to construct the indexes of output and inputs and this procedure is becoming popular in recent Productivity research.

3) In estimating the productivity growth rates, different sub periods can be considered to take into account floods, cyclones, droughts, excessive rainfalls etc.

4) It is also suggested to extend the Productivity studies to other countries to build a inter country productivity comparison.

\section{Conclusion}

Considering the above discussion, it can be said that most of the earlier productivity studies in Bangladesh agriculture sector are based on PFP approach. Among these, a number of studies showed inverse relationship between farm size and productivity. In Bangladesh, agricultural productivity is mostly affected by farm size, tenancy, modern variety rice, modern technology, use of pesticides, concentration of cultivation etc. Since land is the scarcest factor of production in Bangladesh, in recent years agricultural productivity is also concerned with energy efficiency and climate change. Finally it is hoped that this study will identify the gap in research on productivity measurement in Bangladesh agriculture sector and provide the necessary information for future studies.

\section{REFERENCES}

[1] Abedin,J.and G.K.Bose (1988), "Farm Size and Productivity Difference: A Decomposition analysis ", Bangladesh Development Studies, 16(3), 71-79.

[2] Ali, A., .Mushtaq, K., Ashfaq, M\& Raza,M.A (2009) “An analysis of productivity growth of Agriculture in Pakistan:1971-2006", Journal of Agricultural Research, 47(4), 439-450.

[3] Ali, M. (1991), "Factor Substitution and Productivity Change in United Kingdom Agriculture", unpublished Ph.D. thesis, University of Manchester, UK.

[4] Assaduzzaman, M., C. Ringler, J. Thurlow and S. Alam (2010), “Investing in crop agriculture in Bangladesh for higher growth and productivity and Adoption to climate change", Bangladesh Food Security Investment Forum, 26-27 May 2010,Dhaka.

[5] Banerjee, L. (2009), " Flood, Productivity and wage rate in Agriculture: In case of Bangladesh", First draft, March 2009, Department of Economics, The new school for social research, 6 east, 16 th street, New York.

[6] Baset, M.A, M.R. Karim, M. Akhter (2009), "Measurement and Analysis of Total Factor Productivity Growth in Modern Variety Potato", Journal of Agriculture and Rural Development, 7(1\&2), 65-71.

[7] Brown, R.S. (1978), "Productivity, Returns and the Structure of Production in the US Agriculture, 1947-74", unpublished Ph.D. dissertation, University of Wisconsin, Madison.
[8] Christensen, L. R. (1975), “Concepts and Measurement of Agricultural Productivity", American Journal of Agricultural Economics, 57, 910-915.

[9] Coelli, T, S. Rahman and C.Thirtle (2003), "A Stochastic Production Frontier Approach to Total Factor Productivity Measurement in Bangladesh crop Agriculture,1961-1992", Journal of International Development, 15, 321-333.

[10] Dey,M and R.E. Evenson. (1991), “The Economic Impact of Rice Research in Bangladesh", BRRI/ IRRJ/BRAC, Dhaka, Bangladesh 79, 481-507.

[11] Diewert, W.E. (1976), "Exact and Superlative Index Numbers", Journal of Econometrics, 4, 115-145.

[12] Hossain, I. (1990),"Growth Performances of major agricultural crops, Regional Differences in Agricultural Productivity: Implications for Agriculture Planning in Bangladesh", Bangladesh Journal of Political Economy, 11(1) 227-257.

[13] Hossain, M. (1973), "Farm-Size and Productivity in Bangladesh Agriculture: A Case Study of Phulpur Farms", New Series No. 14, Dhaka: Bangladesh Institute of Development Economics.

[14] Hossain, M. (1977),"Farm size, Tenancy and Land Productivity: An analysis of Farm Level Data in Bangladesh Agriculture." Bangladesh Development Studies, 5(3), 285-348.

[15] Hossain, M. (1988), "Nature and Impact of the Green Revolution in Bangladesh", Research Report No.67, Washington DC: International Food Policy Research Institute/ Bangladesh Institute of DevelopmentStudies.

[16] Hossain, M. (1991), Agriculture in Bangladesh: Performance Problems and Prospects, Dhaka: University Press Ltd.

[17] Islam, T.S. (1982), "Input Substitution and Productivity Change in Canadian Agriculture", unpublished Ph.D. dissertation, University of Alberta, Canada.,

[18] Jahan, N. (1997), "Changing Agricultural Productivity in Bangladesh: Its nature and implications for Poverty, Woman, off-farm employment and environment", unpublished Ph.D. dissertation, School of Economics, the University of Queensland.

[19] Khosruzzaman, S., Asgar .m Iqbal, M and Zaved, T., (2008), “Total factor Productivity and Agriculture research relationship: Evidence from crops subsector of Pakistans Panjab", European Journal of scientific research, 66(1), 87-97.

[20] Kiani, A.K., Iqbal, M and Zaved, T., (2008), “Total factor Productivity and Agriculture research relationship: Evidence from crops subsector of $\mathrm{Pa}-$ kistans Panjab", European Journal of scientific research, 66(1), 87-97.

[21] Mandal, M.A.S. (1980),"Farm size, Tenure and Productivity in an Area of Bangladesh", Bangladesh Journal of Agricultural Economics, 3(2), $21-42$.

[22] Matin, K.A. (1989), "Farm-Size, Input Use and Land Productivity o Rice in Bangladesh", Dhaka University Studies, Part C, 10 (1), 37-49.

[23] Pray, C. and Z. Ahmed (1991), "Research and Agricultural Productivity Growth in Bangladesh", in Evenson, R. E, and C. Pray (eds.), Research and Productivity in Asian Agriculture, Cornell University Press, Ithaca.

[24] Rahman, S. (2007), "Regional Productivity and Convergence in Bangladesh Agriculture", The Journal of Developing Areas, 41(1), 221-236, Published by Tennessce state University College of Business.

[25] Sekaran, U., (2002), "Research Methods for Business: A Skilled Building Approach", John Willy \& Sons, New York, pp 25-30.

[26] Sharma, S. (2004), "A study on Productivity performance of Indian Automobile industry : Growth accounting analysis " Paper presented in conference, Centre for efficiency and productivity analysis, University of Queensland, Brisbane, Australia, July 14-16.

[27] Taufique, K. A, (2005), "Farm size and Productivity in Bangladesh Agriculture: Role of Transaction Costs in Rural Labour Markets", Economic and Political Weekly, 40(10), 988-992. 